\title{
Arterial stiffness index beta and cardio-ankle vascular index inherently depend on blood pressure but can be readily corrected
}

Citation for published version (APA):

Spronck, B., Avolio, A. P., Tan, I., Butlin, M., Reesink, K. D., \& Delhaas, T. (2017). Arterial stiffness index beta and cardio-ankle vascular index inherently depend on blood pressure but can be readily corrected. Journal of Hypertension, 35(1), 98-104. https://doi.org/10.1097/HJH.0000000000001132

Document status and date:

Published: 01/01/2017

DOI:

10.1097/HJH.0000000000001132

Document Version:

Publisher's PDF, also known as Version of record

Document license:

Taverne

Please check the document version of this publication:

- A submitted manuscript is the version of the article upon submission and before peer-review. There can be important differences between the submitted version and the official published version of record.

People interested in the research are advised to contact the author for the final version of the publication, or visit the DOI to the publisher's website.

- The final author version and the galley proof are versions of the publication after peer review.

- The final published version features the final layout of the paper including the volume, issue and page numbers.

Link to publication

\footnotetext{
General rights rights.

- You may freely distribute the URL identifying the publication in the public portal. please follow below link for the End User Agreement:

www.umlib.nl/taverne-license

Take down policy

If you believe that this document breaches copyright please contact us at:

repository@maastrichtuniversity.nl

providing details and we will investigate your claim.
}

Copyright and moral rights for the publications made accessible in the public portal are retained by the authors and/or other copyright owners and it is a condition of accessing publications that users recognise and abide by the legal requirements associated with these

- Users may download and print one copy of any publication from the public portal for the purpose of private study or research.

- You may not further distribute the material or use it for any profit-making activity or commercial gain

If the publication is distributed under the terms of Article $25 \mathrm{fa}$ of the Dutch Copyright Act, indicated by the "Taverne" license above, 


\title{
Original Article
}

\section{Arterial stiffness index beta and cardio-ankle vascular index inherently depend on blood pressure but can be readily corrected}

\author{
Bart Spronck $^{\mathrm{a}, \mathrm{b}}$, Alberto P. Avolio ${ }^{a}$, Isabella Tan ${ }^{\mathrm{a}}$, Mark Butlin ${ }^{\mathrm{a}}$, Koen D. Reesink ${ }^{\mathrm{b}}$, and Tammo \\ Delhaas $^{b}$
}

See editorial comment on page 33

Objectives: Arterial stiffness index $\beta$ and cardio-ankle vascular index (CAVI) are widely accepted to quantify the intrinsic exponent $\left(\beta_{0}\right)$ of the blood pressure (BP)-diameter relationship. CAVI and $\beta$ assume an exponential relationship between pressure $(P)$ and diameter $(d)$. We aim to demonstrate that, under this assumption, $\beta$ and CAVI as currently implemented are inherently BP-dependent and to provide corrected, BP-independent forms of CAVI and $\beta$.

Methods and results: In $P=P_{\text {ref }} \mathrm{e}^{\beta_{0}\left[\left(d / d_{\text {ref }}\right)-1\right]}$, usually reference pressure $\left(P_{\text {ref }}\right)$ and reference diameter $\left(d_{\text {ref }}\right)$ are substituted with DBP and diastolic diameter to accommodate measurements. Consequently, the resulting exponent is not equal to the pressure-independent $\beta_{0}$. CAVI does not only suffer from this 'reference pressure' effect, but also from the linear approximation of $(\mathrm{d} P / \mathrm{d} d)$. For example, assuming $\beta_{0}=7$, an increase of SBP/DBP from $110 / 70$ to $170 / 120 \mathrm{mmHg}$ increased $\beta$ by $8.1 \%$ and CAVI by $14.3 \%$. We derived corrected forms of $\beta$ and of $\mathrm{CAVI}\left(\mathrm{CAVI} \mathrm{I}_{0}\right)$ that indeed did not change with $\mathrm{BP}$ and represent the pressure-independent $\beta_{0}$. To substantiate the BP effect on CAVI in a typical follow-up study, we realistically simulated patients $(n=161)$ before and following BP-lowering 'treatment' (assuming no follow-up change in intrinsic $\beta_{0}$ and therefore in actual $P-d$ relationship). Lowering BP from $160 \pm 14 / 111 \pm 11$ to $120 \pm 15 / 79 \pm 11 \mathrm{mmHg}(p<0.001)$ resulted in a significant CAVI decrease (from $8.1 \pm 2.0$ to $7.7 \pm 2.1$, $p=0.008) ; C A V I_{0}$ did not change $(9.8 \pm 2.4$ and $9.9 \pm 2.6$, $p=0.499$ ).

Conclusion: $\beta$ and $\mathrm{CAVI}$ as currently implemented are inherently BP-dependent, potentially leading to erroneous conclusions in arterial stiffness trials. BP-independent forms are presented to readily overcome this problem.

Keywords: arterial stiffness, arteriosclerosis, blood pressure correction, carotid compliance, hypertension, pulse wave velocity

Abbreviations: $A$, artery lumen cross-sectional area; $a, b$, constants relating $\mathrm{CAVI}_{\mathrm{Vs}}$ to $\mathrm{CAVl}$; $\mathrm{BP}$, blood pressure; CAVI, cardio-ankle vascular index as used in this manuscript; $\mathrm{CAVI}_{0}$, pressure-independent CAVI; CAVIVs, CAVI in the Fukuda Denshi VaSera device, related to CAVI in our manuscript by $\mathrm{CAVI}_{\mathrm{Vs}}=a \times C \mathrm{CVI}+b ; d$, artery lumen diameter; $d_{\text {ref }}$, reference diameter; $N(\mu, \sigma)$, independent samples drawn from a normal distribution with mean $\mu$ and SD $\sigma ; P$, blood pressure; $P_{\mathrm{d}}$, DBP; $P_{\mathrm{d}, \mathrm{bl}, \mathrm{nf},}$ $P_{\mathrm{p}, \mathrm{bl}, \mathrm{nf}}, P_{\mathrm{s}, \mathrm{bl}, \mathrm{nf}}$, simulated, noise-free baseline DBP, pulse

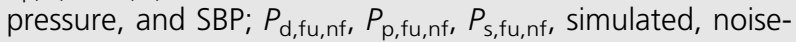
free follow-up DBP, pulse pressure, and SBP; $P_{\text {ref, }}$ reference pressure; $P_{\mathrm{s}}, \mathrm{SBP}$; $\mathrm{PWV}$, pulse wave velocity; $P W V_{\mathrm{bl}, \mathrm{nf}}$, $P W V_{f u, n f}$, simulated, noise-free PWVs at baseline and follow-up; SDC, supplemental digital content $1 ; \beta$, stiffness index beta; $\beta_{0}$, intrinsic, pressure-independent stiffness index beta; $\rho$, blood mass density

\section{INTRODUCTION}

A rterial stiffness, as assessed by pulse wave velocity (PWV), is an important independent predictor for cardiovascular disease. PWV, however, is known to depend intrinsically on arterial blood pressure (BP) $[1,2]$. This BP dependence has led to the search for BP-independent measures of arterial stiffness.

As shown by Hayashi et al. [3], the relationship between arterial pressure and diameter can be described by an exponential function in the physiological range (Fig. 1a). Throughout the present article, this exponential relationship between arterial pressure and diameter with pressureindependent exponent $\beta_{0}$ is assumed as a 'ground truth' on which all other derivations are based. Of note, this article has no intention to prove the validity of this basic assumption.

Journal of Hypertension 2017, 35:98-104

aDepartment of Biomedical Sciences, Faculty of Medicine and Health Sciences, Macquarie University, Sydney, Australia and ${ }^{b}$ Department of Biomedical Engineering, CARIM School for Cardiovascular Diseases, Maastricht University, Maastricht, The Netherlands

Correspondence to Bart Spronck, MSc, Department of Biomedical Engineering, CARIM School for Cardiovascular Diseases, Maastricht University, Universiteitssingel 50 (Room 3.366a), 6229 ER, Maastricht/PO Box 616, 6200 MD, Maastricht, The Netherlands. Tel: +31 43388 1278; fax: +31 43388 1725;

e-mail: b.spronck@maastrichtuniversity.nl

Received 11 May 2016 Revised 8 August 2016 Accepted 19 August 2016 J Hypertens 35:98-104 Copyright (C) 2016 Wolters Kluwer Health, Inc. All rights reserved.

DOI:10.1097/HJH.0000000000001132 

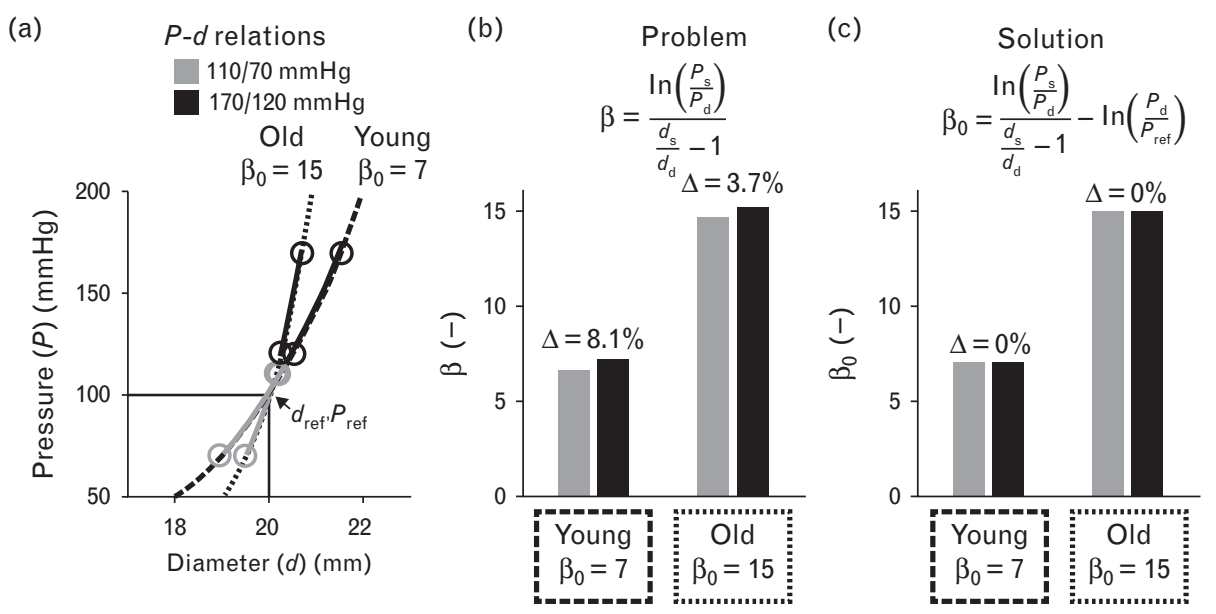

FIGURE 1 Pressure dependence of stiffness index beta ( $\beta$ ). (a) Intrinsic relationship between arterial pressure and diameter [Eq. (1)]. Hayashi et al. [3] showed that in the physiological pressure range, this relationship is exponential. The exponential nature of this relationship is assumed as a 'ground truth' in this article, serving as the basis for all other derivations. Pressure ranges (SBP/DBP) indicated in this panel are used for calculating stiffness parameters in panels $(\mathrm{b})$ and $(\mathrm{c})$. $P_{\text {ref }}=100 \mathrm{mmHg}$ is a reference pressure [Eq. (1)]. $d_{\text {ref }}$ is the diameter corresponding to the reference pressure. $d_{\text {ref }}$ is kept fixed at $20 \mathrm{~mm}$ to illustrate solely the effect of a change in $\beta_{0}$ on the pressurediameter relationship. (b) Measured stiffness index $\beta$, as computed from SBP and DBP $\left(P_{\mathrm{s}}, P_{\mathrm{d}}\right)$ and diameters $\left(d_{\mathrm{s}}, d_{\mathrm{d}}\right)$ on panel (a)'s curves, is blood pressure-dependent. Because the pressure dependence of $\beta$ can be shown to exist mathematically [Eq. (4)], $\beta$ can be corrected using $\ln \left(P_{\mathrm{d}} / P_{\text {ref }}\right)$, obtaining the intrinsic, pressure-independent stiffness index beta $\left(\beta_{0}\right.$, panel c). $P_{\text {ref }}$ and $d_{\text {ref, }}$ reference blood pressure and diameter corresponding to Eq. (1).

Kawasaki et al. [4] proposed a clinically usable stiffness index $\beta$ that is based on the exponential relationship as demonstrated by Hayashi et al. [3]. In the present article, we will demonstrate that $\beta$ is only an approximation of $\beta_{0}$, and that $\beta$ is in fact pressure-dependent.

Cardio-ankle vascular index (CAVI) is being increasingly used in small and large population studies [5] and is advocated as a pressure-independent index of arterial stiffness [6]. CAVI is closely related to stiffness index $\beta$ and is also an approximation of the exponent of the pressurediameter relationship. Although $\beta$ is used for local characterization of small artery segments, CAVI is derived as a summary measure for the heart-to-ankle arterial trajectory. CAVI is obtained by measuring PWV and converting it into an index using the Bramwell-Hill equation [1].

In the present article, we will:

1. Show that $\beta$, as commonly calculated in biomedical literature, is not equal to the actual, intrinsic stiffness index of the pressure-diameter relationship $\left(\beta_{0}\right)$ but instead varies with BP.

2. Show that the BP dependence of $\beta$ can be corrected for, yielding a formula to obtain the true, intrinsic stiffness index $\beta_{0}$ from the same measurements.

3. Show that CAVI, which essentially is a form of stiffness index $\beta$, is also BP dependent.

4. Show that a straightforward modification of the formula for calculating CAVI yields a pressureindependent version, that is, $\mathrm{CAVI}_{0}$.

5. Illustrate the scientific and clinical relevance of our analysis and proposed corrected $\beta_{0}$ and $\mathrm{CAVI}_{0}$ formulas.

\section{METHODS}

\section{Behaviour of the arterial wall: intrinsic stiffness index beta}

Hayashi et al. [3] showed experimentally that, in the physiological BP range, arterial pressure $(P)$ and diameter (d) relate exponentially:

$$
P=P_{\mathrm{ref}} e^{\beta_{0}\left[\left(d / d_{\mathrm{ref}}\right)-1\right]} .
$$

Throughout this article, this equation serves as our 'ground truth'. $\beta_{0}$ in this relationship is an intrinsic, pressureindependent measure of arterial stiffness. Note the use of $P_{\text {ref }}$ (a 'reference' or 'standard' pressure) in this equation. $d_{\text {ref }}$ is the diameter corresponding to the reference pressure. Figure 1a shows two pressure-diameter relationships obtained using Eq. (1) at $\beta_{0}=7$ and 15. Each curve corresponds to one $\beta_{0}$ value. $P_{\text {ref }}=100 \mathrm{mmHg}$ was used throughout the present study [3].

\section{Assessment of arterial wall mechanics: measured stiffness index beta}

Stiffness index $\beta$ as commonly reported is calculated using a slightly different equation than Eq. (1):

$$
P_{\mathrm{S}}=P_{\mathrm{d}} e^{\beta\left[\left(d_{\mathrm{s}} / d_{\mathrm{d}}\right)-1\right]},
$$

in which $P_{\mathrm{s}}, d_{\mathrm{s}}, P_{\mathrm{d}}$, and $d_{\mathrm{d}}$ denote SBP and DBP and diameters, respectively. Note the following differences between Eqs. (1) and (2): (i) reference pressure and diameter have been changed to DBP and diameter; (ii) instantaneous variable pressure has been changed to SBP; and (iii) intrinsic stiffness index $\beta_{0}$ has been changed to measured stiffness $\beta$.

Eq. (2) can be rearranged to obtain the commonly used expression for $\beta$ :

$$
\beta=\frac{\ln \left(P_{\mathrm{s}} / P_{\mathrm{d}}\right)}{\left(d_{\mathrm{s}} / d_{\mathrm{d}}\right)-1} .
$$

If this equation is used to quantify $\beta$ in an exponentiallydistending wall [Eq. (1)] with a given $\beta_{0}=7$ and $P_{\text {ref }}=100 \mathrm{mmHg}$, calculated $\beta$ s will be dependent on the 
pressure ranges (Fig. 1b). This can be understood as follows.

\section{Pressure dependence of measured stiffness index $\beta$}

Suppose that two pressure-diameter points are measured on the intrinsic pressure-diameter relationship [Eq. (1)]: a systolic $\left(P_{\mathrm{s}}, d_{\mathrm{s}}\right)$ and a diastolic $\left(P_{\mathrm{d}}, d_{\mathrm{d}}\right)$ point. From Eq. (3) and rearranging the result [Supplemental digital content 1 (SDC), http://links.lww.com/HJH/A682], we obtain

$$
\beta=\beta_{0}+\ln \left(\frac{P_{\mathrm{d}}}{P_{\text {ref }}}\right) .
$$

This equation shows that $\beta$, the measured stiffness index, differs from the intrinsic stiffness index $\beta_{0}$, by an amount of $\ln \left(P_{\mathrm{d}} / P_{\text {ref }}\right)$. This also implies that we can readily obtain the intrinsic, pressure-independent stiffness index $\beta_{0}$ by rearranging Eq. (4):

$$
\beta_{0}=\beta-\ln \left(\frac{P_{\mathrm{d}}}{P_{\text {ref }}}\right) .
$$

Note that if $P_{\mathrm{d}}$ is equal to $P_{\text {ref }}, \ln \left(P_{\mathrm{d}} / P_{\text {ref }}\right)=0$, and $\beta_{0}$ equals $\beta$. However, in general, this is not the case.

Substituting the initial expression for $\beta$ [Eq. (3)] into Eq. (5) yields

$$
\beta_{0}=\frac{\ln \left(P_{\mathrm{s}} / P_{\mathrm{d}}\right)}{\left(d_{\mathrm{s}} / d_{\mathrm{d}}\right)-1}-\ln \left(\frac{P_{\mathrm{d}}}{P_{\mathrm{ref}}}\right),
$$

which is a formulation that can be used to obtain the intrinsic, pressure-independent stiffness index $\beta_{0}$ from measured SBP and DBP and diameters.

\section{The value of reference pressure}

The previous sections demonstrate that the pressure (either $P_{\mathrm{d}}$ or $\left.P_{\text {ref }}\right)$ that is used to multiply the exponential function influences the value of $\beta$ or $\beta_{0}$ that is obtained. It is important to realize that a value of $\beta_{0}$ corresponds to a $P_{\text {ref }}$ value. Therefore, one should choose one, fixed $P_{\text {ref }}$ value for all patients in a study, to be able to compare the $\beta_{0}$ values among these patients. The numerical value of $P_{\text {ref }}$ that is chosen is a matter of standardization or consensus. $P_{\text {ref }}$ does not represent a physiological pressure. Different values of $P_{\text {ref }}$ (and the corresponding $d_{\text {ref }}$ ) lead to different values of $\beta_{0}$. However, the $P-d$ curves that are described using these different combinations of $P_{\text {ref }} / d_{\text {ref }} / \beta_{0}$ perfectly and analytically overlap. Therefore, $P_{\text {ref }}$ values should be taken equal between studies (irrespective of the patient cohort studied), if $\beta_{0}$ values are to be compared between those studies. Arbitrarily, in the present study, we have chosen $P_{\text {ref }}=100 \mathrm{mmHg}$.

\section{Cardio-ankle vascular index}

Stiffness index $\beta$ [Eq. (3)], which is a function of pressures $\left(P_{\mathrm{d}}\right.$ and $\left.P_{\mathrm{s}}\right)$ and diameters $\left(d_{\mathrm{d}}\right.$ and $\left.d_{\mathrm{s}}\right)$, can also be expressed as a function of pressures and PWV. This is accomplished by combining Eq. (3) with a simplified version of the Bramwell-
Hill equation (SDC Eq. S10) [1]. When PWV in this equation is determined from the heart-to-ankle arterial bed, the resulting quantity (in fact a $\beta$ index) is termed CAVI:

$$
\mathrm{CAVI}=\ln \left(\frac{P_{\mathrm{s}}}{P_{\mathrm{d}}}\right) \times \frac{\mathrm{PWV}^{2} \times 2 \rho}{P_{\mathrm{s}}-P_{\mathrm{d}}} .
$$

PWV from the heart to the ankle is obtained using a combination of the phonocardiography, electrocardiography, and brachial and ankle cuff measurements [6].

For the same reasons outlined in the previous section (the use of DBP instead of a reference BP), CAVI is pressure dependent. However, CAVI also depends on BP for another reason, as explained below.

The derivation of CAVI [6] is based on a simplified version of the Bramwell-Hill equation (Fig. 2b), in which the derivative of pressure to diameter $(\mathrm{d} P / \mathrm{d} d)$ is replaced by a linear approximation over the DBP-to-SBP range. This approximation introduces an error in the obtained CAVI value. The magnitude of this error can be quantified using the true PWV, that is, the PWV based on the true $(\mathrm{d} P / \mathrm{d} d)$ in the diastolic point (SDC Eq. S11). Using this PWV to calculate CAVI by means of Eq. (7) yields

$$
\text { CAVI }=\left[\beta_{0}+\ln \left(\frac{P_{\mathrm{d}}}{P_{\text {ref }}}\right)\right] \times \ln \left(\frac{P_{\mathrm{s}}}{P_{\mathrm{d}}}\right) \times \frac{P_{\mathrm{d}}}{P_{\mathrm{s}}-P_{\mathrm{d}}} .
$$

The extra terms beside $\beta_{0}$ on the right-hand side of this equation indicate the pressure dependence of CAVI (Fig. 2c).

\section{Finding a pressure-independent cardio-ankle vascular index}

A pressure-independent CAVI formula should provide an index equivalent to the intrinsic stiffness index $\beta_{0}$. Such an index can be derived by squaring and rearranging the relationship between true PWV (obtained from the exact, analytic derivative of the $P-d$ relationship) and $\beta_{0}$ (SDC Eq. S13):

$$
\mathrm{CAVI}_{0}=\beta_{0}=\frac{\mathrm{PWV}^{2} \times 2 \rho}{P_{\mathrm{d}}}-\ln \left(\frac{P_{\mathrm{d}}}{P_{\text {ref }}}\right) .
$$

This equation can be used to obtain the pressureindependent $\mathrm{CAVI}_{0}$ from PWV, $\rho$, and $P_{\mathrm{d}}$ (Fig. 2d).

\section{Simulations}

\section{Residual blood pressure dependence of stiffness index $\boldsymbol{\beta}$ and cardio-ankle vascular index}

To quantify the BP dependence of stiffness index $\beta$, we calculated $\beta$ [Eq. (4)] at two clearly distinct BP ranges [normotensive 110/70 $\mathrm{mmHg}(\mathrm{SBP} / \mathrm{DBP})$ and hypertensive $170 / 120 \mathrm{mmHg}]$. We did so for two values of intrinsic stiffness: $\beta_{0}=7$ and $\beta_{0}=15$, corresponding to a normal young patient and an older patient with a stiffened artery, respectively. The reference diameter $\left(d_{\text {ref }}\right)$ was kept constant at $20 \mathrm{~mm}$. The quantitative effect of BP on CAVI was determined for the same BP ranges and $\beta_{0}$ values [Eq. (8)]. 
(a)

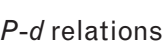

$110 / 70 \mathrm{mmHg}$

$170 / 120 \mathrm{mmHg}$ (b)

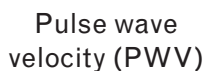

velocity (PWV)

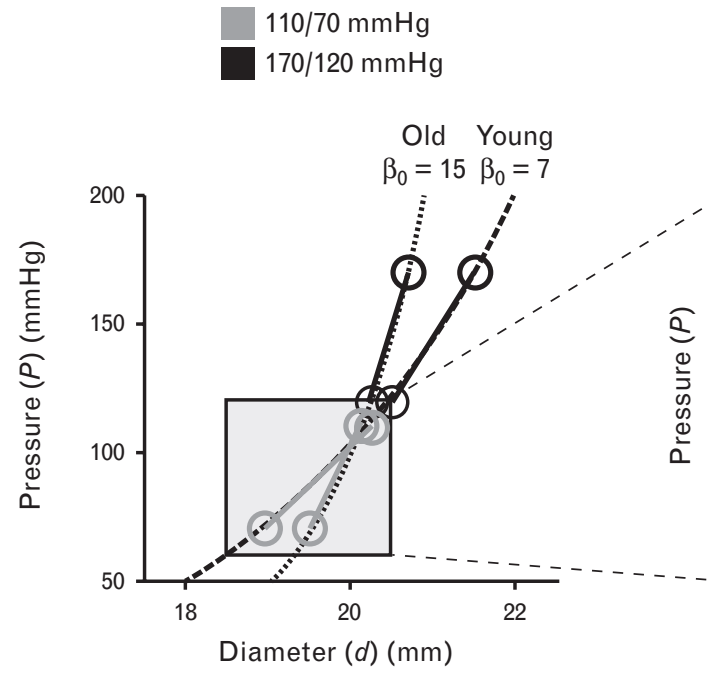

$\mathrm{PWW}=\sqrt{\frac{\mathrm{d} P}{\mathrm{~d} d} \frac{d}{2 \rho}}$

(c)

Problem

(d)

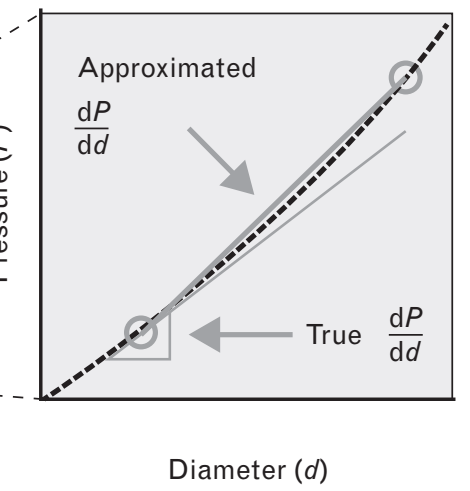

$$
\text { CAVI }=\ln \left(\frac{P_{\mathrm{s}}}{P_{\mathrm{d}}}\right) \cdot \frac{\mathrm{PWV}^{2} \cdot 2 \rho}{P_{\mathrm{s}}-P_{\mathrm{d}}}
$$
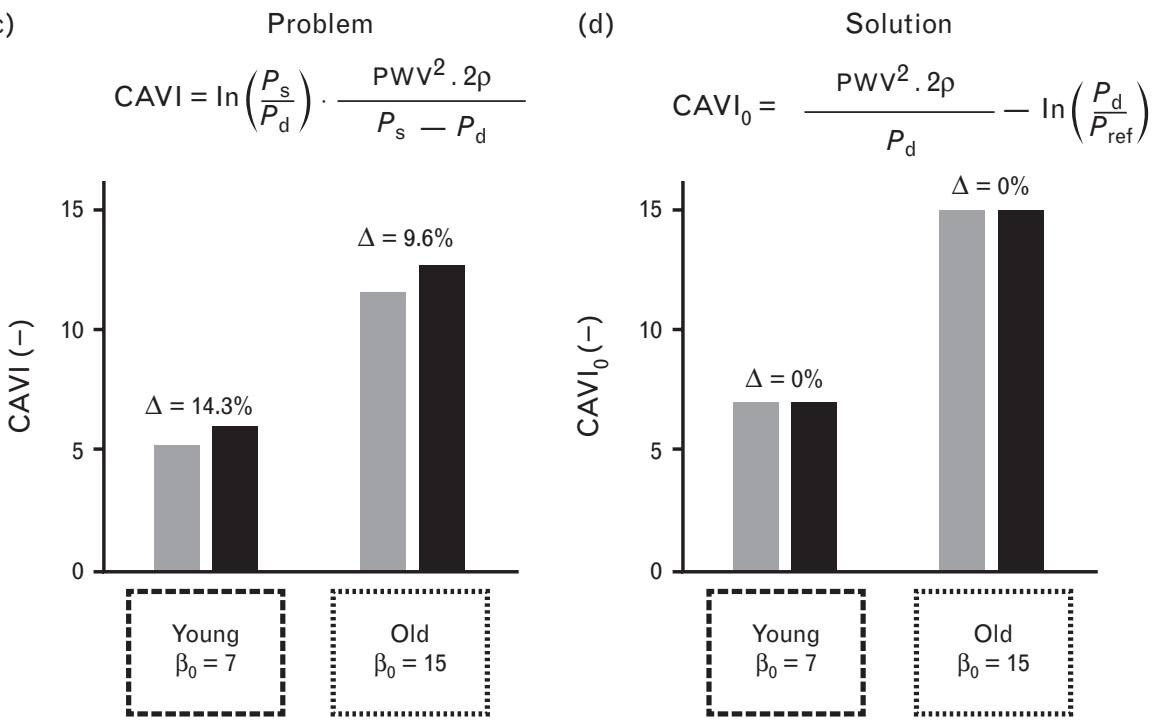

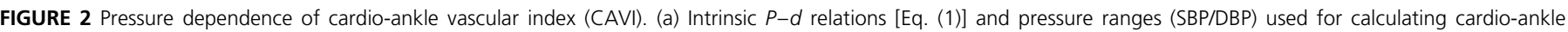

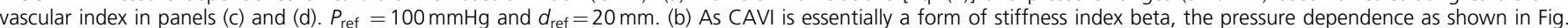

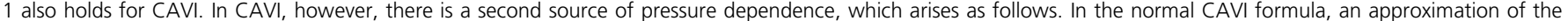
Bramwell-Hill equation is used, effectively substituting $\mathrm{d} P / \mathrm{d} d$ with $\Delta P / \Delta d$. Therefore, if CAVI is determined using measured pulse wave velocity and the standard

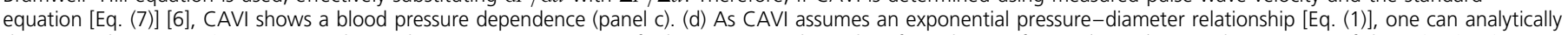

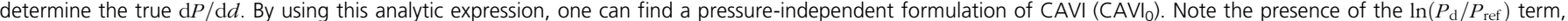
which is also present in the corrected form of stiffness index beta [Eq. (6) and Fig. 1c]. $P_{\text {ref }}$ and $d_{\text {ref, }}$ reference blood pressure and diameter corresponding to Eq. (1).

\section{Blood pressure dependence of cardio-ankle vascular index in a simulated population study}

To gain insight into the magnitude of the BP dependence of CAVI and how this could affect a typical study's results, we computer-simulated a BP-lowering treatment in a population with an average intrinsic stiffness of $\beta_{0}=10$. For a detailed description of the protocol for data generation and randomization, we refer the reader to the SDC.

In short, we simulated a baseline and a follow-up measurement between which BP decreased on average from about $160 / 110$ to $120 / 80 \mathrm{mmHg}$. Importantly, we assumed wall behaviour to remain unchanged. That is, with the BP change for each patient, the exponential
$P-d$ relationship [Eq. (1)] and, hence, $\beta_{0}$ remained unchanged. DBP, SBP, and PWV values before and following 'treatment' were drawn from normal distributions, simulating biological variation. Subsequently, measurements were simulated by adding normally distributed measurement noise. CAVI and $\mathrm{CAVI}_{0}$ were calculated from these simulated measurements.

Using the simulated population data, we calculated the sample size at which, for a power of $80 \%$ and $\alpha=0.05$, the BP lowering would lead to a statistically significant change in CAVI. Subsequently, we simulated a study in the number of patients obtained from the sample size calculation to illustrate a typical study's results. 


\section{RESULTS}

\section{Residual blood pressure dependence of stiffness index $\boldsymbol{\beta}$ and cardio-ankle vascular index}

Figure $1 \mathrm{~b}$ shows the quantitative effect of $\mathrm{BP}$ on stiffness index $\beta$. With increasing BP from $110 / 70$ to $170 / 120 \mathrm{mmHg}$ (SBP/DBP), $\beta$ increased by $8.1 \%$ (from 6.6 to 7.2 ) in a young individual's artery with $\beta_{0}=7$. In an older individual's artery with $\beta_{0}=15, \beta$ increased by $3.7 \%$ (from 14.6 to 15.2 ).

Pressure dependence of $\beta$ was markedly smaller than that of PWV. PWV changed to a much larger extent with BP; from 5.4 to $7.4 \mathrm{~m} / \mathrm{s}$ in the young artery (36\% change) and from 8.1 to $10.8 \mathrm{~m} / \mathrm{s}$ in the older artery (33\% change). Stiffness index $\beta$ as determined using the corrected equation [Eq. (6), yielding $\beta_{0}$ ] was independent of pressure (Fig. 1c).

Figure 2c shows the quantitative effect of BP on CAVI. With increasing BP from $110 / 70$ to $170 / 120 \mathrm{mmHg}$ (SBP/DBP), CAVI increased from 5.3 to 6.0 (14.3\% increase) in a young individual and from 11.6 to 12.7 (9.6\% change) in an older individual. Furthermore, using the standard CAVI formula leads to much lower values for $\beta$ than the actual, intrinsic $\beta_{0}$ s of 7 and 15 .

CAVI as determined using the corrected equation [Eq. (9), yielding $\left.\mathrm{CAVI}_{0}\right]$ was independent of pressure (Fig. 2d).

Figure 3 shows how stiffness index $\beta$ (a) and CAVI (b) depend on DBP and SBP. Comparing Fig. 3a and b, one sees that (i) $\beta$ only depends on DBP, whereas CAVI depends on DBP and SBP; and that (ii) the BP dependence of CAVI is much larger than that of $\beta$ (viz., compare the different colour scales of panes a and b). The larger $\mathrm{BP}$ dependence of CAVI is caused by the use of an approximated derivative in the CAVI formula (Fig. 2b), in addition to the 'reference pressure' effect that affects both $\beta$ and CAVI.

\section{Simulated impact of the blood pressure dependence of cardio-ankle vascular index in a population study}

For our simulated population, we determined that a sample size of 161 patients would give an $80 \%$ chance of finding a statistically significant difference in CAVI due to BP lowering. Table 1 shows the results of a simulated set of measurements in 161 patients. Values throughout are expressed as mean $\pm \mathrm{SD}$.

For the lowering of SBP from $160 \pm 14$ to $120 \pm 15 \mathrm{mmHg}$ $(p<0.001)$ and DBP from $110 \pm 11$ to $79 \pm 11 \mathrm{mmHg}$ $(p<0.001)$, PWV significantly decreased from $8.2 \pm 1.1$ to $6.9 \pm 1.0 \mathrm{~m} / \mathrm{s}(p<0.001)$. CAVI as calculated from the standard equation [Eq. (7)] significantly decreased from $8.1 \pm 2.0$ to $7.7 \pm 2.1(p=0.008)$ with lowering BP, as expected for the sample size.

The corrected CAVI as proposed and calculated from Eq. (9) $\left(\mathrm{CAVI}_{0}\right)$ showed no change with $\mathrm{BP}(p=0.499)$.

\section{DISGUSSION}

CAVI and $\beta$ assume an exponential relationship between pressure and diameter. In this study, we have demonstrated that, under this assumption and contrary to the often made claim [6], stiffness index $\beta$ and CAVI are BP dependent. This confirms findings by Lim et al. [7], who showed a BP dependence of CAVI in an experimental setting. However, the BP dependence of other artery stiffness parameters, such as PWV [2], is greater than that of $\beta$ and CAVI.

Using CAVI under the assumption of it being fully BPindependent may confound conclusions, especially in large population studies investigating relatively small changes in CAVI. For example, several studies have reported that arterial stiffness, as measured with CAVI, decreases with BP-lowering medication [5,8]. However, our simulations show that even in a study with relatively few participants $(n=161)$ in which intrinsic wall parameters $\left(\beta_{0}\right)$ were explicitly kept constant, the BP effect on CAVI may emerge as statistically significant.

In our simulation study, the BP effect on PWV $(1.3 \mathrm{~m} / \mathrm{s})$ is much larger than the within-patient SD of $0.5 \mathrm{~m} / \mathrm{s}$ [9]. The $\mathrm{BP}$-induced change of CAVI of 0.4 in our simulation study is of the same order as the CAVI within-patient SD of 0.5 [10]. This comparison underlines the much smaller BP dependence of CAVI when compared with PWV and emphasizes that CAVI as usually implemented may lead to erroneous conclusions.
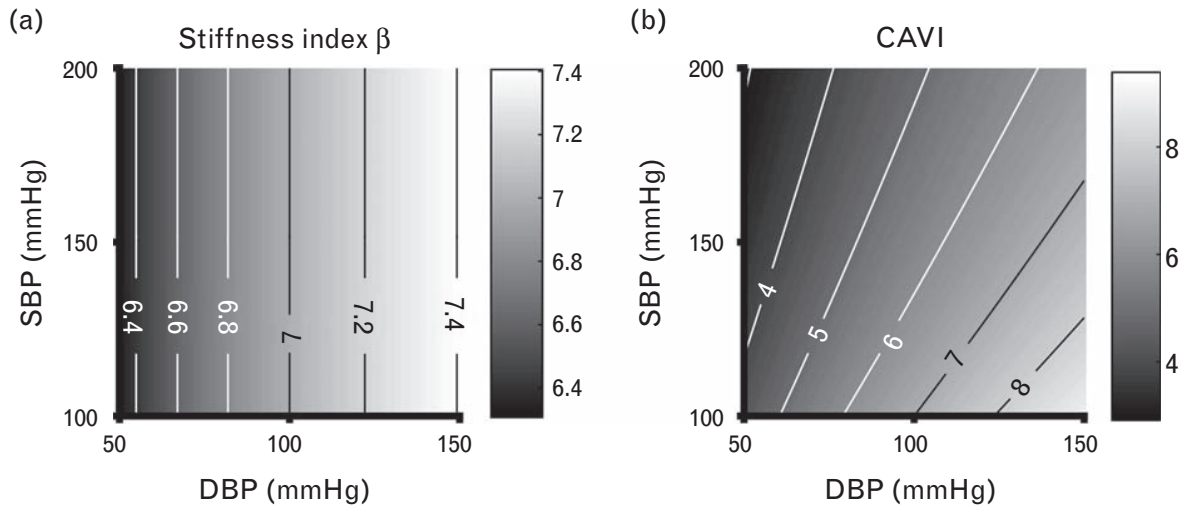

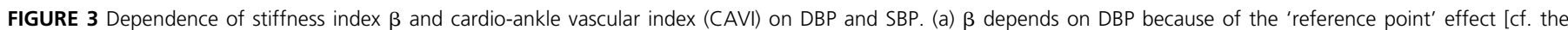
difference between Eqs. (1) and (2)]. (b) The 'reference point' effect also influences CAVI, causing a dependence of CAVI on DBP. CAVI is additionally blood pressure-

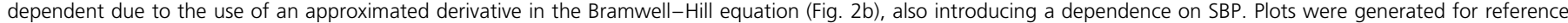
pressure $=100 \mathrm{mmHg}$ and $\beta_{0}=7$ (see text). 
TABLE 1. Uncorrected cardio-ankle vascular index leads to misinterpretation

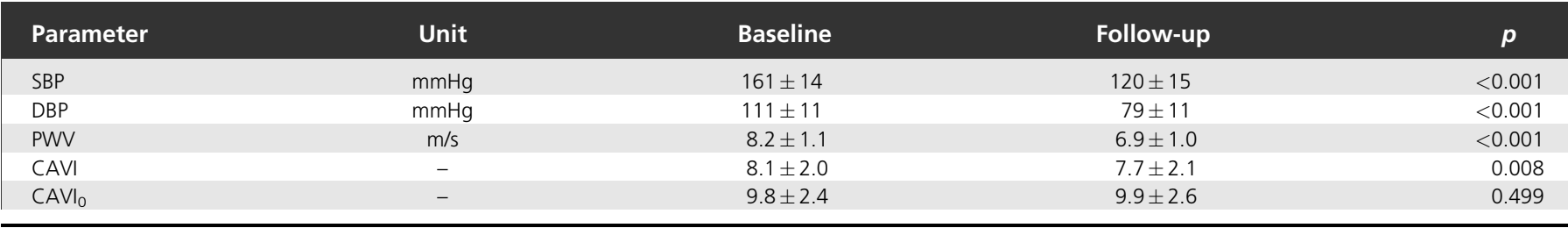

Pressure dependence of CAVI in a simulated data set $(n=161)$. Values denote mean \pm SD. CAVI, standard, pressure-dependent cardio-ankle vascular index [Eq. (7)]; CAVI 0 , corrected,

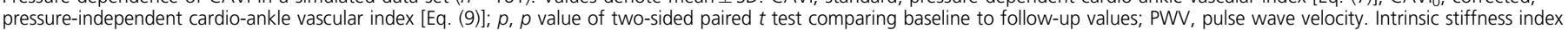
$\beta_{0}$ was $9.8 \pm 1.9$, and was equal at baseline and follow-up.

As mentioned in the introduction, Kawasaki et al. $[4,11]$ previously derived $\beta$ from $\beta_{0}$. In their derivation, they correctly mentioned that clinically, it is difficult to measure diameter at a standard pressure of for example, $100 \mathrm{mmHg}$. After this notice, they simplified Eq. (1) to Eq. (2), thereby neglecting the underlying BP dependence emerging from substituting DBP and diastolic diameter for $P_{\text {ref }}$ and $d_{\text {ref }}$ in Eq. (1).

Note that CAVI as reported by the VaSera device by Fukuda Denshi, Co. Ltd (Tokyo, Japan) $\left(\mathrm{CAVI}_{\mathrm{VS}}\right)$ is a scaled version of CAVI as used in this article: CAV$\mathrm{I}_{\mathrm{VS}}=a \times \mathrm{CAVI}+b[6]$. The constants $a$ and $b$ are considered proprietary information by the company and therefore are not publically available. However, as $a$ and $b$ constants, the BP dependence of CAVI is equally applicable to $\mathrm{CAVI}_{\mathrm{Vs}}$.

The present study relies on the assumption that the in vivo arterial wall pressure-diameter relationship is exponential. The underlying arterial wall mechanics of the exponential behaviour are complex. At lower pressures, mainly elastin bears the load, whereas at higher pressures, this load bearing is gradually shifted to collagen $[12,13]$. This shift leads to the typical form of the full $P-d$ relationship, which, starting from $P=0$, first shows an increase in compliance, then has a maximum, and subsequently decreases with increasing pressure [14]. The maximum compliance, corresponding to an inflection point in the $P-d$ relationship, occurs at a pressure of around $45 \mathrm{mmHg}$ in individuals aged 30 years. With increasing age, the pressure at which the maximum compliance occurs decreases and becomes $0 \mathrm{mmHg}$ at the age of 80 [15]. If this full $P-d$ relationship with an inflection point is to be described, a single-exponential $P-d$ relationship is clearly insufficient; an arctangent-type model may be more suitable in this case [14].

Because young patients have an inflection point at relatively high pressures of $\approx 45 \mathrm{mmHg}$, the assumption of a single-exponential relationship may not hold when they are hypotensive. In this case, their low DBPs may be close to their inflection point. However, in all other patients, physiological BPs are normally well above the inflection point. Therefore, a single-exponential relationship provides an appropriate approximation of the true $P-d$ relationship.

The exponential shape of the $P-d$ relationship as shown in vitro by Hayashi et al. [3] was confirmed in vivo in humans by Stefanadis et al. [16]. They reported that the pressure-diameter data fitted excellently to the monoexponential function $P=b \times \mathrm{e}^{a \times D},(r=0.97-0.99, p<0.001)$, ...' in the human aorta, both in normotensive and hypertensive patients. Later studies by these investigators again confirmed this finding $[17,18]$.
The choice of an exponential $P-d$ relationship has a pragmatic reason. Models that are more complicated than the single-exponential model cannot be uniquely parameterized using a set of SBP and DBP and two diameters or a PWV. This limits their use to very specific research studies in which the full pressure-diameter relationship is measured, or in which more than two $P-d$ points are measured (e.g. by adding an additional dicrotic notch point [19]). In our opinion, this limitation, together with the in-vivo validations by Stefanadis et al. [16], makes a strong case for using an exponential model to characterize in vivo arterial $P-d$ relationships.

\section{GONGLUSION}

CAVI and stiffness index $\beta$ rely on the assumption of an exponential relationship between pressure and diameter. In this article, we have shown that, under this assumption, stiffness index $\beta$ and CAVI as commonly implemented depend on BP. This dependence can potentially lead to erroneous conclusions in studies that use $\beta$ and CAVI to estimate changes in stiffness of the artery wall. We have presented corrected stiffness indices, $\beta_{0}$ and $\mathrm{CAVI}_{0}$, that readily overcome this problem.

\section{Perspectives}

The findings presented in this manuscript have direct implications for all studies that incorporate $\beta$ and/or CAVI measurements. We have shown that due care should be taken in interpreting $\beta$ and CAVI as strictly pressureindependent measures of arterial stiffness. In a moderately sized study, a BP decrease from a hypertensive to a normotensive range may lead to a significant decrease in CAVI as calculated from the standard equation, merely due to the change in $\mathrm{BP} . \mathrm{CAVI}_{0}$, as derived in the present study, does not exhibit this pressure dependence. Our new formulations $\left(\beta_{0}\right.$ and $\left.C A V I_{0}\right)$ allow even retrospective data analysis for improved interpretation of arterial stiffness trials. Recently, we have shown that the degree of BP dependence of PWV is clinically relevant [2], and that the BP dependence is apparent from the PWV reference values [20]. Based on the reference values for PWV, and considering the approach proposed in the present article, pressure-independent reference values for $\beta_{0} / \mathrm{CAVI}_{0}$ could be obtained.

\section{ACKNOWLEDGEMENTS}

The study was supported by a Kootstra Talent Fellowship awarded to B. Spronck by Maastricht University. 


\section{Conflicts of interest}

There are no conflicts of interest.

\section{REFERENGES}

1. Bramwell JC, Hill AV. The velocity of the pulse wave in man. Proc R Soc Lond B Biol Sci 1922; 93:298-306.

2. Spronck B, Heusinkveld MH, Vanmolkot FH, Roodt JO, Hermeling E, Delhaas T, et al. Pressure-dependence of arterial stiffness: potential clinical implications. J Hypertens 2015; 33:330-338.

3. Hayashi K, Handa H, Nagasawa S, Okumura A, Moritake K. Stiffness and elastic behavior of human intracranial and extracranial arteries. J Biomech 1980; 13:175-184.

4. Kawasaki T, Sasayama S, Yagi S, Asakawa T, Hirai T. Noninvasive assessment of the age related changes in stiffness of major branches of the human arteries. Cardiovasc Res 1987; 21:678-687.

5. Saiki A, Sato Y, Watanabe R, Watanabe Y, Imamura H, Yamaguchi T, et $a l$. The role of a novel arterial stiffness parameter, cardio-ankle vascular index (CAVI), as a surrogate marker for cardiovascular diseases. J Atheroscler Thromb 2016; 23:155-168.

6. Shirai K, Utino J, Otsuka K, Takata M. A novel blood pressure-independent arterial wall stiffness parameter; cardio-ankle vascular index (CAVI). J Atheroscler Thromb 2006; 13:101-107.

7. Lim J, Pearman ME, Park W, Alkatan M, Machin DR, Tanaka H. Impact of blood pressure perturbations on arterial stiffness. Am J Physiol Regul Integr Comp Physiol 2015; 309:R1540-R1545.

8. Shirai K, Song M, Suzuki J, Kurosu T, Oyama T, Nagayama D, et al. Contradictory effects of beta1- and alpha1-aderenergic receptor blockers on cardio-ankle vascular stiffness index (CAVI) - CAVI independent of blood pressure. J Atheroscler Thromb 2011; 18 49-55.

9. Salvi P, Magnani E, Valbusa F, Agnoletti D, Alecu C, Joly L, et al. Comparative study of methodologies for pulse wave velocity estimation. J Hum Hypertens 2008; 22:669-677.

10. Kubozono T, Miyata M, Ueyama K, Nagaki A, Otsuji Y, Kusano K, et al. Clinical significance and reproducibility of new arterial distensibility index. Circ J 2007; 71:89-94.
11. Hirai T, Sasayama S, Kawasaki T, Yagi S. Stiffness of systemic arteries in patients with myocardial infarction. A noninvasive method to predict severity of coronary atherosclerosis. Circulation 1989; 80:78-86.

12. O'Rourke MF, Hashimoto J. Mechanical factors in arterial aging: a clinical perspective. J Am Coll Cardiol 2007; 50:1-13.

13. Spronck B, Heusinkveld MH, Donders WP, de Lepper AG, Op't Roodt $\mathrm{J}$, Kroon AA, et al. A constitutive modeling interpretation of the relationship among carotid artery stiffness, blood pressure, and age in hypertensive subjects. Am J Physiol Heart Circ Physiol 2015; 308:H568-582.

14. Langewouters GJ, Wesseling KH, Goedhard WJ. The static elastic properties of 45 human thoracic and 20 abdominal aortas in vitro and the parameters of a new model. J Biomech 1984; 17:425-435.

15. Wesseling G, Langewouters K, Goedhard W. A new model for the static elastic properties of the aging human aorta. Cardiovascularphysiology heart, peripheral circulation and methodology: proceedings of the 28th International Congress of Physiological Sciences, Budapest, 1980 1980; 8:271.

16. Stefanadis C, Dernellis J, Vlachopoulos C, Tsioufis C, Tsiamis E, Toutouzas K, et al. Aortic function in arterial hypertension determined by pressure-diameter relation: effects of diltiazem. Circulation 1997; 96:1853-1858.

17. Stefanadis C, Dernellis J, Tsiamis E, Stratos C, Kallikazaros I, Toutouzas P. Aortic function in patients during intra-aortic balloon pumping determined by the pressure-diameter relation. $J$ Thorac Cardiovasc Surg 1998; 116:1052-1059.

18. Toutouzas K, Stefanadis C, Tsiamis E, Vlachopoulos C, Tousoulis D, Tsioufis C, et al. Aortic pressure-diameter relation in patients with noninsulin dependent diabetes mellitus: new insights. Diabetologia 2000; 43:1070-1075.

19. Hermeling E, Hoeks AP, Winkens MH, Waltenberger JL, Reneman RS, Kroon AA, et al. Noninvasive assessment of arterial stiffness should discriminate between systolic and diastolic pressure ranges. Hypertension 2010; 55:124-130.

20. Reference Values for Arterial Stiffness' Collaboration. Determinants of pulse wave velocity in healthy people and in the presence of cardiovascular risk factors: 'establishing normal and reference values'. Eur Heart J 2010; 31:2338-2350. 